Оксана Парфенова

\title{
СОЦИАЛЬНЫЕ СЕРВИСЫ ДЛЯ ПОЖИЛЫХ: ФОРМАЛЬНЫЕ И НЕФОРМАЛЬНЫЕ ПРАВИЛА И ПРАКТИКИ
}

Статья посвящена одному из ключевых направлений отечественной социальной политики - социальному обслуживанию пожилых граждан. Крупнейшим агентом в этой сфере со стороны государства являются комплексные центры социального обслуживания населения (КЦСОН). Объектом исследования методом кейс-стади выступает КЦСОН одного из районов Санкт-Петербурга. Я проанализировала как функционирует этот сервис, рассмотрев совокупность связанных с ним формальных и неформальных правил и практик. Забота о пожилом человеке со стороны КЦСОН оформлена в виде набора услуг, которые предоставляются за плату (относительно невысокую на момент проведения исследования). Этот набор услуг во многом одобряется самими клиентами. Со стороны социальных работников существует неформализованное представление о том, что входит в их обязанности, а что нет. При этом, их должностная инструкция базируется на устаревшей версии закона о социальном обслуживании. Таким образом, в ходе исследования выявлено расхождение должностных инструкций и с действующим законодательством, и с реальными практиками. Кроме того, в ходе обслуживания не происходит качественного изменения социального статуса пожилого человека. КЦСОН частично подменяет своей помощью те функции, которые обычно выполняют сами пожилые или их близкие. Такое «делегирование» заботы профессионалам позволяет пожилым людям отчасти компенсировать потерю трудоспособности и физической активности и поддерживать определенный образ жизни. При этом в ряде случаев надомное социальное обслуживание может вписываться в модель «теплой современной заботы», когда функции по уходу за пожилым человеком разделены между институтом (КЦСОН) и семьей.

Оксана Парфенова - ассоциированный научный сотрудник Центра арктических и сибирских исследований, Социологический институт ФНИСЦ РАН, научный сотрудник НИУ ИТМО, Санкт-Петербург, Россия. Электронная почта: oksana.parfenova@gmail.com 
Ключевые слова: социальная политика; социальные сервисы; пожилые; социальное исключение

DOI: $10.17323 / 727-0634-2017-15-4-573-588$

Современный демографический контекст характеризуется стремительным увеличением доли пожилых людей во многих развитых странах. Россия не является исключением. Параллельно с общим снижением численности населения, доля пожилых ${ }^{1}$ граждан в демографической структуре возрастает. Так, в 1990 г. она составляла $19 \%$ от общей численности населения, и, постепенно возрастая, к 2015 г. достигла почти 24\% (Росстат 2015). Увеличение числа пожилых требует и изменения социальной политики в этой области. Одним из ответов стало создание в 1990-е гг. специализированных социальных сервисов для пожилых граждан - Комплексных центров социального обслуживания населения (КЦСОН или ЦСО). Первоначально КЦСОН предоставляли широкий спектр социальных услуг всем категориям населения (семьям с детьми, людям с инвалидностью, пожилым гражданам). В Санкт-Петербурге, начиная середины 2000-х гг. (Постановление Правительства Санкт-Петербурга 2006), они начали переходить на обслуживание преимущественно пожилых граждан как отдельной целевой группы.

У данного типа учреждений накопился опыт работы с пожилыми. Однако практики и эффекты социального обслуживания пожилых оставались за рамками внимания исследователей. Данное исследование призвано внести вклад в изучение работы одного из государственных институтов, на базе которого реализуется социальная политика в отношении пожилых граждан. Основной вопрос касается соотношения нормативных и реально сложившихся практик и правил социальных служб, работающих с пожилыми людьми. Для ответа на этот вопрос я кратко рассмотрю историю становления социальных сервисов, отдельно остановлюсь на методологии исследования, и затем на эмпирических материалах проанализирую практики обслуживания на дому в отдельно взятом КЦСОН.

\section{Изменения законодательства в сфере социального обслуживания}

Трансформации российского законодательства в области социального обслуживания начались уже после создания соответствующих служб в постсоветском периоде. Поначалу социальные службы были ориентированы на помощь разным категориям населения. В рамках государственного

\footnotetext{
1 В рамках работы определение «пожилые» употребляется как возрастная характеристика граждан, достигших пенсионного возраста, установленного законодательством РФ (55 лет для женщин и 60 лет для мужчин).
} 
сервиса и в качестве одной из первых его функций появляется надомная помощь пожилым гражданам. Тогда же появляются и первые социальные работники, задачей которых стало обслуживание пожилых граждан и инвалидов на дому. Однако правовое оформление эта профессия получает чуть позже уже в связи с введением в действие и изменениями законов о социальном обслуживании населения (Федеральный закон 1995a; 1995b). В этом законодательстве закладываются основные направления социальной политики в отношении разных категорий граждан, оказавшихся в трудной жизненной ситуации:

Трудная жизненная ситуация - ситуация, объективно нарушающая жизнедеятельность гражданина (инвалидность, неспособность к самообслуживанию в связи с преклонным возрастом, болезнью, сиротство, безнадзорность, малообеспеченность, безработица, отсутствие определенного места жительства, конфликты и жестокое обращение в семье, одиночество и тому подобное), которую он не может преодолеть самостоятельно (Федеральный закон 1995а: Ст. 3).

Положение пожилых граждан в этом контексте связывается, в первую очередь, с неспособностью к самообслуживанию. Вслед за новым законодательством появляются социальные службы, специализирующиеся в том числе на работе с пожилыми людьми. Как правило, они оформлялись в «Комплексный центр социального обслуживания населения» (КЦСОН), выделяясь из структуры районных отделов социальной защиты населения. Первоначально эти центры специализировались на социальной поддержке всех категорий населения. Однако, начиная с 2000 г., КЦСОН постепенно переходят на работу преимущественно с пожилыми гражданами и инвалидами. Так, в «Концепции развития системы социальной защиты населения Санкт-Петербурга на 2006-2010 года», говорится о необходимости четко разделять социальные сервисы на три группы: учреждения социального обслуживания граждан пожилого возраста, учреждения социальной реабилитации инвалидов и учреждения социального обслуживания семьи и детей. В первую группу учреждений как раз и были включены КЦСОН (Постановление Правительства Санкт-Петербурга 2006).

Таким образом, в задачу КЦСОН включена специализированная помощь пожилым людям и инвалидам. При этом помимо минимально необходимой адресной поддержки пожилых людей (например, помощь в уборке квартиры, доставка продуктов питания, получение медикаментов), на базе учреждений существуют клубные объединения, ориентированные на групповые занятия и досуг. Согласно программным установкам Министерства труда, социальное обслуживание направлено на улучшение качества жизни пожилых людей и включает мероприятия по организации персонализированной помощи и коллективного досуга для них (Постановление Министерства труда 1999). В этом контексте улучшение качества жизни можно понимать как преодоление социального исключения и стрем- 
ление к социальному включению. Другими словами, это стремление если не вернуть, то хотя бы улучшить социальный статус, который заметно снижается у пожилого неработающего гражданина.

Также в 2004 г. введен ГОСТ о социальном обслуживании населения (Постановление Госстандарта 2003), который распространяется на социальные услуги, оказываемые населению со стороны государственных, муниципальных и других учреждений. ГОСТ устанавливает основные виды социальных услуг и требования к их оказанию. Этот документ выступал в качестве основания при разработке внутренней документации центров социального обслуживания: договора с клиентом и должностных инструкций социального работника.

В 2015 г. вступил в силу закон об основах социального обслуживания, который заметно меняет правила игры: вводится индивидуальная программа обслуживания и возрастает плата за него. Поскольку эмпирическая часть исследования ограничена 2014 г., то анализ охватывает период работы вплоть до вступления в силу нового закона, не затрагивая последующие трансформации. Несмотря на то что период сбора эмпирического материала в рамках моего исследования ограничен 2010-2014 гг., фактически результаты анализа практик надомного обслуживания пожилых граждан можно с некоторыми оговорками экстраполировать на весь период действия Федерального закона о социальном обслуживании от 1995 г.

\section{Теоретическая и методологическая база исследования}

Исследование выполнено в рамках методологии изучения случая (кейсстади). Объект представляет собой характерную для Санкт-Петербурга организацию социального обслуживания. На протяжении исследования я занимала позицию стороннего исследователя-наблюдателя. Полевая часть проводилась в период с января 2010 г. по июнь 2014 г. Все материалы собраны и проанализированы в рамках этнографического кейс-стади (Романов 2005). Эмпирическими материалами послужили 28 интервью с клиентами КЦСОН, социальными работниками, заведующими отделений, а также дневники наблюдений за взаимодействием социальных работников с пожилыми клиентами во время надомного обслуживания. Кроме того, проанализированы ключевые внутренние документы организации: должностные инструкции, формы договоров, акты обследования материально-бытового положения, положения о работе отделений.

Для анализа положения пожилых граждан используются категории социального исключения/уязвимости и гражданства. Социальное исключение имеет процессуальный характер и влечет ограничение возможностей гражданина (Abrahamson 2004; Tikhonova 2004). Категория социального исключения активно разрабатывается и применяется как иностранными (Сен 2004), так и отечественными исследователями 
(Дмитриева 2012; Григорьева, Чернышова 2009). Ситуация социального исключения по мере развития может сопровождаться изменением гражданского и социального статуса человека. Клиенты КЦСОН - пожилые граждане - рассматриваются как находящиеся в ситуации возможности многомерного социального исключения, которое связано с утратой профессиональных и родственных связей, ухудшением материального положения и физического здоровья (Tikhonova 2004).

Объект исследования - КЦСОН - рассматривается как совокупность практик и формальных и неформальных правил (Гидденс 2005). Это означает, что КЦСОН анализируется как организация, имеющая определенную структуру и функционирующая посредством распределения имеющихся ресурсов. КЦСОНы характеризуются практиками, которые выражаются во взаимодействии центров со своими клиентами. При этом структура и правила поведения определяются разноуровневыми нормативами (формальными правилами): законодательные акты, положения о работе КЦСОН, формы договоров с клиентами. Действующие лица, в свою очередь, способны порождать латентные правила (неформальные), либо принципиально новые, либо на основе имеющихся.

В рамках данного исследования, я не только анализирую формальные правила, в которых выражены функции учреждения, но основной упор сделан на изучении неформальных правил взаимодействия. Услуги, предоставляемые КЦСОН (главным образом - надомное обслуживание) рассматриваются в категориях заботы. Последняя интерпретируется как «особый вид работы, выполняемый в рамках определенных социальных и экономических отношений» (Чернова 2011:297). Если говорить о моделях заботы, то за основу берутся выделенные Арли Хохшильд (Hochschild 2003): «традиционная» (осуществляется в рамках семьи, основной поставщик заботы - женщина); «постсовременная» (практики заботы сочетаются с занятостью женщин на рынке труда); «современная холодная забота» (забота о детях и пожилых осуществляется государственными/частными институтами); «современная теплая забота» (часть заботы на институтах, часть - на мужчинах и женщинах, членах одной семьи). В заключении я дам ответ на вопрос о том, какой из этих моделей соответствует социальное обслуживание пожилых в России.

\section{Обязанности социального работника и клиента: формальные инструкции и практики}

В этом разделе я рассмотрю официальные документы (формальные правила), которые непосредственно регламентируют практики надомного обслуживания и покажу, как они соотносятся с реальными практиками. В ходе исследования обнаружено несоответствие внутренних должностных инструкций социального работника и действующего на тот момент закона 
о социальном обслуживании. Первоначальная версия закона о социальном обслуживании граждан пожилого возраста гласила:

Социальное обслуживание граждан пожилого возраста и инвалидов представляет собой деятельность по удовлетворению потребностей указанных граждан в социальных услугах. Социальное обслуживание включает в себя совокупность социальных услуг (уход, организация питания, содействие в получении медицинской, правовой, социальнопсихологической и натуральных видов помощи, помощи в профессиональной подготовке, трудоустройстве, организации досуга, содействие в организации ритуальных услуг и другие), которые предоставляются гражданам пожилого возраста и инвалидам на дому или в учреждениях социального обслуживания независимо от форм собственности (Федеральный закон 1995b: Ст. 1).

Однако все эти пункты, раскрывающие понятие «социального обслуживания», исключены из новой редакции закона (Федеральный закон 2004). Они сохранились в действующей в период проведения исследования должностной инструкции социального работника, которая является приложением к договору и выдается каждому клиенту (Должностная инструкция 2008а). Фактически, инструкция базируется на более ранней версии закона - 1995 г. Это подтверждают и руководство исследуемого КЦСОН, которое в качестве опорных нормативных документов использует три закона: «О социальном обслуживании граждан пожилого возраста и инвалидов» (1995a) и «Об основах социального обслуживания населения в Российской Федерации» (1995b), а также Постановление Минтруда «Об утверждении методических рекомендаций по организации деятельности государственного (муниципального) учреждения "Комплексный центр социального обслуживания населения"» (1999). Кроме того, в СанктПетербурге закон о социальном обслуживании на момент исследования не был принят, существовало только постановление о взимании платы, которым КЦСОН также руководствовался. А закон «О государственных стандартах социального обслуживания населения Санкт-Петербурга» (2008) лишь уточняет перечень стандартов социальных услуг и социальных групп, которые могут эти услуги получить.

Интервью с клиентами и социальными работниками, а также наблюдения показывают, что основные обязанности, которые выполняют социальные работники (реальные практики) включают в себя два вида услуг, регламентированых должностными обязанностями (формальными правилами). Главная услуга - это покупка и доставка продуктов и лекарств. Клиент заказывает социальному работнику продукты и тот приносит их два раза в неделю, стараясь при этом соблюсти требования клиента (например, определенный сорт молока или сосиски «подешевле»). Однако соблюдать требования получается не всегда, поскольку социальный работник часто закупает продукты в одном месте и затем нагруженный разносит их 
«по адресам», что само по себе накладывает определенные ограничения. Иногда социальный работник идет навстречу клиенту и, например, отоваривается в отдаленной аптеке, где лекарства дешевле (Инт 2СР).

Второй распространенный тип услуг - помощь в оформлении документов (заявления на льготы, получение справок, запись на прием к врачу) и оплата коммунальных счетов. При оплате счетов социальный работник имеет право обслуживания без очереди. Но, по словам социальных работников, они редко пользуются этой возможностью, поскольку очередь «возмущается». При этом на вопрос о том, почему не производят оплату через терминал, соцработники отвечали, что терминал не дает сдачи, а цифры за услуги «не круглые» и «докажи потом этим бабушкам, что тыл все как надо уплатил, да и не доверяют многие этим чекам, любят по старинке, чтобы на квитанции отмечено было» (Инт СР 3).

Таким образом, из того объема обязанностей, прописанных в должностной инструкции, социальный работник выполняет лишь небольшую часть. Это отнимает много времени, поскольку минимальное количество клиентов, которых нужно обслуживать 2-3 раза в неделю одному социальному работнику для полной ставки - восемь человек. За каждого дополнительного клиента идет небольшая доплата, поэтому некоторые берут больше клиентов. При этом практики социальных работников совпадают частично, а частично могут не совпадать с действующими должностными обязанностями. Так, например, несмотря на то что «содействие в организации ремонта и уборки жилых помещений, помощь в приготовлении пищи» входят в должностные обязанности, на практике это не реализуется и, более того, воспринимается самими клиентами как дополнительные услуги, за которые нужно платить.

Это подтверждают интервью, в которых клиенты и социальные работники рассказывают о латентных практиках платежей и подарков за «сверх» работу. Одна из информанток - социальный работник - (неохотно) называет расценки за неформальную помощь: за то, чтобы убрать однокомнатную квартиру и помочь пожилому человеку помыться она берет 1000 рублей (Инт 2 СР). Судя по частому употреблению в этом контексте слова «бабушки» во множественном числе, таких клиентов у нее несколько. На обслуживании у нее состоит восемь человек (пять женщин и трое мужчин), но для некоторых ее клиентов такие услуги слишком дороги.

Сами клиенты считали часть услуг, которые им оказывают представители КЦСОН «дополнительными», в то время как они входят в должностные обязанности. Так, например, двое клиентов считают вынос мусора и выемку газет из почтового ящика той «неформальной заботой», которую ему оказывает социальный работник исключительно из личной симпатии и хорошего отношения (Инт 2П, Инт 3 П). Примечательно, что эти клиенты - мужчины. В другом интервью о расценках на «дополнительные» услуги рассказывает клиентка: 
В: А мыться Вам помогает кто-то?

O: Вот насчет мыться мы с ней [социальным работником] договорились, но это очень дорого, что мне... я сама могу помыться, потереть, но это большую цену она спросила, я сейчас не могу такую цену заплатить.

В: А вообще сколько попросила она?

О: Ну, это дорого... не знаю это как... как личная услуга $<\ldots>500$ рублей (Инт 5П).

Наряду с доходом за такую «неформальную заботу», социальный работник получает доход за ту «неформальную заботу», которая входит в его формальные обязанности. Уборка в квартире (однокомнатной) стоит 500 рублей. И, хотя в инструкции социального работника непосредственно уборка помещения не прописана, а указывается лишь «содействие» в ее организации, то в другой инструкции - для работника специализированного отделения с маломобильными/лежачими клиентами - в обязанности вменяется «помощь в уборке», что воспринимается социальными работниками как услуга, возможная только за отдельную плату. Также они выступают посредниками между своими знакомыми, готовыми убираться за плату, и пожилыми клиентами, нуждающимися в уборке. То же самое относится к приготовлению пищи, которая для обычного и специализированного отделений обслуживания на дому значится как обязанность, но в интервью преподносится социальными работниками как редкий «бонус» для пожилых клиентов. Такая трансформация формальных правил в достаточно урезанный набор реальных практик, позволяет социальному работнику не только заработать, но и получать благодарность от клиентов за «сверхурочные».

В интервью с соцработниками нередко упоминалось о практиках «фиктивного» обслуживания, когда пожилые мужчины и женщины - знакомые и соседи соцработника или его подопечных - становились клиентами КЦСОН, не нуждаясь при этом в его услугах. В этом случае социальный работник получал за дополнительного клиента надбавку, но реально обслуживание не производилось, либо услуги оказывались реже, чем положено по договору. Плата за обслуживание при этом либо не взымалась, поскольку клиент относился к льготной категории, либо составляла символическую сумму, которую по договоренности иногда мог компенсировать сам социальный работник. Но в связи с изменением принципов оплаты за социальное обслуживание и заметным увеличением его стоимости, отмены большинства льгот, подобная схема утратила свою актуальность.

Кроме того, соцработники занимаются посредничеством между клиентом и третьей стороной (часто знакомым социального работника), которая оказывает платные услуги клиенту. Одна из информанток (социальный работник) рассказала историю о том, как нашла компаньонку для своей пожилой клиентки. На эту роль она пригласила свою соседку, которая 
за отдельную плату помогает бабушке, ограниченной в движении после болезни. Каждый день она ездит готовить ей еду и кормит (Инт $2 \mathrm{CP}$ ). Здесь стоит отметить, что разговор о неформальных платежах воспринимается информантами достаточно остро: социальные работники или неохотно признаются в том, что взымают дополнительную плату (Инт 2 СР), либо категорически отрицают возможность каких-либо неформальных материальных обменов с клиентом:

В: Бывает так, что вы выполняете просьбы клиента, которые в общем не входят в тот список, за который вам зарплату платят?

O: Ну смотря что. Если Вы имеете ввиду работу по дому, там, мытье окон, я конечно это не делаю. <..> Может там кто-то хочет договариваться, но я не делаю.

В: Ну а за дополнительную плату?

О: Ну, я нет. У меня дома хватает этих забот... Ну, вот у меня есть одна бабушка совершенно ненормальная, слепая. Я ей там пересыпаю сахар, один раз ей жарила котлеты, открываю консервные банки... А вообще у нас есть специализированное медицинское отделение, если человеку совсем уже плохо, то к нему ходят другие соцработники, которые помогают по дому, медсестра ходит (Инт 1 СР).

В этой цитате, с одной стороны, информант дистанцируется от практик, которые предполагают неформальные платежи, а с другой, указывает на то, что оказывает бесплатно некоторую помощь, которая, по ее мнению, не входит в список должностных обязанностей. Нередко руководство центров напрямую запрещает предоставлять некоторые услуги, включенные в должностные инструкции соцработника. Так, в должностных инструкциях прописаны услуги, которые включают помощь в приготовлении еды, однако руководство конкретного отделения не поощряет подобное ввиду возрастающей ответственности:

Я им запрещаю то, что связано со здоровьем (готовить еду, мыть пожилых и т.п.), все, что не касается здоровья, мы делаем. Даже ногти говорю не подстригать, потому что бывают люди с диабетом. Их можно поранить и это будет чревато (Инт 1 Э).

При этом заведующая добавляет, что у самих социальных работников и медсестер «нет стимула» к тому, чтобы выполнять слишком большой объем работы, поскольку у них «оплата почасовая и мотивации нет». Она предполагает, что с введением «рациональных наборов» (когда зарплата работника будет зависеть от количества выполненных услуг) ситуация может измениться. Стоит отметить, что, начиная с 2014 г. с введением индивидуальных программ обслуживания, набор услуг и количество времени, выделяемое на них изменились и продолжают меняться, что требует дополнительного изучения. 
Со стороны клиентов также нарушаются некоторые формальные правила - например, положения договора об оказании услуг. В частности, один из пунктов договора гласит, что «обслуживаемый» обязуется: «Производить предоплату заказываемых продуктов, медикаментов, предметов первой необходимости, за оплату услуг и платежей» (Договор, п.2.2.3). Однако, по словам руководства, предоплату производят примерно $40 \%$ клиентов, а в остальных случаях социальные работники вынуждены покупать все на свои деньги, и возмещение затрат клиентом происходит только после получения непосредственно заказанного товара (Инт 1 Э). Это также подтверждается и в интервью с социальными работниками (Инт 1 СР, Инт 2 СР).

Стоит также отметить, что на практики обслуживания влияют и гендерные параметры поля социального обслуживания. Подавляющее большинство социальных работников - женщины. Большинство клиентов, обслуживаемых на дому - также женщины (количество мужчин составляет примерно $14 \%{ }^{1}$ от общего числа клиентов). При этом, согласно наблюдениям, взаимодействия социальных работников с клиентами-мужчинами отличаются от тех ситуаций, когда в роли клиента выступает женщина. Один из клиентов-мужчин сообщил, что иногда дарит социальному работнику подарки или дает деньги, потому что она «хорошо работает» (Инт 2П). Этот мужчина ценит независимость в отношениях с соцработником: не позволяет вымыть за собой чашку, после того, как угостит ее чаем, сам готовит себе разнообразную еду, убирает в квартире. Другая информантка - социальный работник, которая практикует платные услуги, акцентирует внимание на том, что помогает только «бабушкам», а про мужчин говорит: «Они у меня сильные, не просят, сами справляются. А я еще их подбадриваю! Говорю, что молодцьы такие, и они все сами делают» (Инт 2Э).

Обобщая, следует отметить, что социальные работники склонны оценивать свою работу как «воспитывающую внимание». Они приводят примеры того, как в некоторых случаях делают для пожилого человека гораздо больше, чем близкие родственники (в том числе и в плане эмоционального участия). Работа оценивается социальными работниками и руководством КЦСОН как эмоционально напряженная, приводящая к эффекту профессионального выгорания. Бывают случаи, когда клиент умирает на глазах у социального работника, и это чревато не только эмоциональными проблемами, но и юридическими.

\section{Заключение}

Социальный сервис институцинально устроен таким образом, чтобы обслуживать преимущественно «пассивных» клиентов на дому. В ходе

\footnotetext{
${ }^{1}$ По данным КЦСОН на 2011 г.
} 
обслуживания не происходит качественного изменения социального статуса пожилого человека. Можно предположить, что он закрепляется в статусе исключенного, то есть нуждающегося в постоянной поддержке и заботе профессионала. С другой стороны, социальные услуги помогают держаться на плаву, т.е. не происходит «обрушения» социального статуса клиента. КЦСОН частично берет на себя те функции, которые раньше лежали на самом пожилом человеке и на его близких. Такое «делегирование» заботы по жизнеобеспечению профессионалам позволяет отчасти компенсировать потерю трудоспособности и физической активности и поддерживать привычный образ жизни.

Забота о пожилом человеке со стороны КЦСОН оформлена в виде конкретного набора услуг, которые ему предоставляются за плату (относительно не высокую на момент проведения исследования - плата редко превышала 200-250 рублей в месяц). Этот набор услуг во многом востребован самими клиентами. У социальных работников существует собственное представление о том, что входит в их обязанности. Эти представления не совпадают с должностной инструкцией, которая, в свою очередь, не соответствует текущему законодательству, а базируется на более ранней версии закона о социальном обслуживании. Таким образом, в ходе исследования выявлено расхождение должностных инструкций и с действующим законом, и с реальными практиками.

Со стороны клиентов - пожилых граждан - исходит согласие с тем набором услуг, которые им предоставляются, но та часть, которая входит в обязанности социального работника согласно как старой, так и новой версии закона, воспринимается как неформальная забота. Кроме того, распространены практики неформальных платежей за «дополнительные» услуги, входящие в должностную инструкцию социального работника (уборка в квартире, например). Сами клиенты тоже могут нарушить формальные правила (не внести предоплату).

Данную сферу институциональной заботы можно охарактеризовать как ту, где основными поставщиками и получателями услуг являются женщины. Если говорить о моделях заботы, предложенных Хохшильд, то сложно однозначно охарактеризовать изучаемое социальное обслуживание как сферу «холодной современной заботы», которая предполагает длительное или постоянное нахождение в специализированных учреждениях (в случае с пожилыми - это дома престарелых, например). В ряде случаев надомное социальное обслуживание вписывается в модель «теплой современной заботы», когда функции по уходу за пожилым человеком разделены между институтом (КЦСОН) и семьей.

С начала 2014 г., после вступления в силу нового Закона о социальном обслуживании происходят некоторые изменения в социальной сфере. Введение платы за социальное обслуживание и расширение спектра предоставляемых услуг приводит, с одной стороны, к уменьшению клиентов 
социального сервиса (от обслуживания отказываются «фиктивные» клиенты), с другой стороны - к изменению практик обслуживания и требует дальнейшего изучения с привлечением нового эмпирического материала.

\section{Выражения признательности}

Исследование выполнено в Университете ИТМО на средства гранта Российского научного фонда (проект № 14-18-03434. Продлен на 2017-2018): «Модели взаимодействия общества и пожилых людей: исследование возможностей социальной инклюзии».

\section{Список полевых данных:}

Интервью с заведующими отделений КЦСОН:

Инт $1 Э$ (заведующая отделением социально-медицинского обслуживания на дому, дата проведения: 27.01.2010);

Инт 2 Э (заведующая отделением социального обслуживания на дому, дата проведения: 27.01.2010).

Интервью с социальными работниками:

Инт 1 СР, социальный работник отделения социального обслуживания на дому, женщина, 50 лет. Дата проведения: 19.01.2010;

Инт 2 СР, социальный работник отделения социального обслуживания на дому, женщина, 55 лет. Дата проведения: 27.01.2010.

Интервью с клиентами КЦСОН (обслуживаемые на дому в отделении социального обслуживания на дому):

Инт 1 П, женщина, 79 лет, Дата проведения: 19.01.2010;

Инт 2П, мужчина, 72 года, Дата проведения: 25.01.2010;

Инт 3 П, мужчина, 75 лет, Дата проведения: 12.02.2010;

Инт 4П, женщина, 80 лет, Дата проведения: 15.02.2010;

Инт 5 П, женщина, 77 лет, Дата проведения: 22.02.2010.

Дневники наблюдения:

Дневник 1 - взаимодействие социального работника (Инт $1 \mathrm{CP})$ и клиента (Инт 1 П) Дата наблюдения: 19.01.2010;

Дневник 2 - взаимодействие социального работника (Инт $1 \mathrm{CP}$ ) и клиента (Инт 2 П). Дата наблюдения: 25.01.2010;

Дневник 6 - взаимодействие социального работника (Инт 2 СР) и клиента пожилого мужчины (нет интервью). Дата наблюдения: 27.01.2010.

\section{Внутренние документы КЦСОН:}

Договор о социальном обслуживании граждан пожилого возраста и инвалидов отделением социальной помощи на дому на условиях частичной (или полной) оплаты.

Должностная инструкция социального работника отделения социального обслуживания на дому граждан пожилого возраста и инвалидов (а). Утверждена 10 декабря 2008 года директором ГУ КЦСОН *** района СПб.

Должностная инструкция социального работника отделения социальномедицинского обслуживания на дому граждан пожилого возраста и инвалидов (b). Утверждена 10 декабря 2008 года директором ГУ КЦСОН *** района СПб. 


\section{Список источников}

Гидденс Э. (2005) Устроение общества. Очерк теории структурациии. 2-е изд., М.: Академический Проект.

Григорьева И.А., Чернышова С. П. (2009) Новые подходы к профилактике социального исключения пожилых. Журнал социологии и соичильной антропологии, 2 (12): 186-196.

Дмитриева А.В. (2012) Социальное включение и исключение как принцип структурации современного общества. Социологический журнал, (2): 98-115.

Закон Санкт-Петербурга (2008) О государственных стандартах соииального обслуживания населения Санкт-Петербурга от 30.01.2008.

Постановление Госстандарта (2003) Социальное обслуживание населения. Основные виды социальных услуг №327-ст от 24.11. 2003.

Постановление Министерства труда (1999) Об утверждении методических рекомендаций по организации деятельности государственного (мунииипального) учреждения «Комплексный иентр соииального обслуживания населения № 32 от 27.07.1999.

Постановление Правительства Санкт-Петербурга (2006) О Концепции развития системы соииальной защиты населения Санкт-Петербурга на 2006-2010 годы №559 от 16.05.2006 г.

Романов П.В. (2005) Стратегия кейс-стади в исследовании социальных служб. Социологические исследования, (4): 101-110.

Росстат (2015) Численность пенсионеров и средний размер назначенных пенсий по видам пенсионного обеспечения и категориям пенсионеров на 1 января 2015 года. Доступно по ссылке: http://www.gks.ru/free_doc/new site/population/urov/urov p2.htm (дата обращения: 19 июня 2017).

Сен А. (2004) Развитие как свобода, М.: Новое издательство.

Федеральный закон (1995а) Об основах соииального обслуживания населения в Российской Федеращии № 195-ФЗ от 10.12.1995.

Федеральный закон (1995b) О соичальном обслуживании граждан пожилого возраста и инвалидов № 122-ФЗ от 02.08.1995.

Федеральный закон (2013) Об основах социального обслуживания граждан в Российской Федерации № 442-ФЗ от 28.12.2013.

Чернова Ж. В. (2011) Кто, о ком и на каких условиях должен заботиться? Гендерный анализ режимов заботы и семейной политики. Журнал исследований соичиальной политики, 9 (3): 295-318.

Abrahamson P. (2004) Social Exclusion: Concepts and Debates. N. Manning, N. Tikhonova (eds.) Poverty and Social Exclusion in the New Russia, Burlington: Ashgate: 95-109.

Hochschild A. (2003) The Commercialization of the Intimate Life: Notes from Home and Work, Berkeley, CA: University of California Press.

Tikhonova N. (2004) Social exclusion in Russia. N. Manning, N. Tikhonova (eds.) Poverty and Social Exclusion in the New Russia, Burlington: Ashgate: 109-149. 
Oksana Parfenova

\section{SOCIAL SERVICES FOR THE ELDERLY: FORMAL AND INFORMAL RULES AND PRACTICES}

The article analyses one of the key directions of current domestic social policy: social service for senior citizens. The largest state social service agent is the Complex Centre of Social Services (KTSSON). The empirical object of the case study is the KTSSON of one of the St. Petersburg districts. We analysed how this service functions, considering it as a set of formal and informal rules and practices. Caring for an elderly person by the KTSSON is framed as a very specific set of services that are provided for a fee. This set of services is largely approved by the customers themselves. From the side of social workers there is clear view of what is their duty and what is not. At the same time, their ideas do not coincide with the official job description, which, in turn, is based on an earlier version of the law on social service. Thus, in the course of the study, a discrepancy emerges between official instructions, current law and real practices. Furthermore, there is no qualitative change in the social status of an elderly person as a result of the service. KTSSON partially takes on the functions that other elderly people or family members carried out. This 'delegation' of care to social work professionals partly compensates for losing the ability to work and conduct physical activity. Thus, in some cases, home-based social services may well fit into the model of 'warm modern care,' where the functions of caring for the elderly are divided between an institution (KTSSON) and the family.

Key words: social policy; social services; elderly; social exclusion

DOI: $10.17323 / 727-0634-2017-15-4-573-588$

\section{References}

Abrahamson P. (2004) Social Exclusion: Concepts and Debates. N. Manning, N. Tikhonova (eds.) Poverty and Social Exclusion in the New Russia, Burlington: Ashgate: 95-109.

Chernova Zh.V. (2011) Kto, o kom i na kakikh usloviyakh dolzhen zabotit'sya? Gendernyy analiz rezhimov zaboty i semeynoy politiki [Who, Who and on What Terms should Take Care of? Gender Analysis of Caring and Family Policy Regimes]. Zhurnal issledovaniy sotsial'noy politiki [The Journal of Social Policy Studies], 9(3):295-318.

Oksana Parfenova - associate researcher, Federal Center of Theoretical and Applied Sociology of the Russian Academy of Sciences, Saint Petersburg, Russian Federation. Email: oksana. parfenova@gmail.com 
Decree of the State Standard (2003) Sotsial'noe obsluzhivanie naseleniya. Osnovnye vidy sotsial'nykh uslug [Social Services for the Population. Main Types of Social Services] N 327-st from 24.11.2003.

Decree of the Ministry of Labor (1999) Ob utverzhdenii metodicheskikh rekomendatsiy po organizatsii deyatel'nosti gosudarstvennogo (munitsipal'nogo) uchrezhdeniya 'Kompleksnyy tsentr sotsial'nogo obsluzhivaniya naseleniya' [On the Methodological Recommendations for the Organization of the State (Municipal) Institution 'Complex Center of Social Services'] No. 32 from 27.07.1999.

Dmitrieva A. V. (2012) Sotsial'noe vklyuchenie i isklyuchenie kak printsip strukturatsii sovremennogo obshchestva [Social inclusion and exclusion as the principle of the structure of modern society]. Sotsiologicheskiy zhurnal [Sociological Journal], 2:98-115.

Federal Law (1995a) Ob osnovah sotsyalnogo obsluzhivaniya naselenia v Rossiyskoy Federatsii [On the Foundations of Social Service for the Population of the Russian Federation] No. 195-FZ from 10.12.1995.

Federal Law (1995b) O sotsial'nom obsluzhivanii grazhdan pozhilogo vozrasta i invalidov [On Social Services for Elderly People and Disabled People] No. 122-FZ from 02.08.1995 (ed. 22.08.2004).

Federal Law (2013) Ob osnovah sotsyalnogo obsluzhivaniya grazhdan v Rossiyskoy Federatsii [On the Foundations of Social Service for the Citizens of the Russian Federation] No. 442-FZ from 28.12.2013.

Giddens E. (2005) Ustroenie obshchestva. Ocherk teorii strukturatsii [The Constitution of Society: Outline of the Theory of Structuration]. 2nd Ed., Moscow: Akademicheskiy Proekt.

Grigor'eva I. A., Chernyshova S.P. (2009) Novye podkhody k profilaktike sotsial'nogo isklyucheniya pozhilykh [New approaches to the prevention of social exclusion of the elderly]. Zhurnal sotsiologii i sotsial'noy antropologii [The Journal of Sociology and Social Anthropology], 2 (12): 186-196.

Hochschild A. (2003) The Commercialization of the Intimate Life: Notes from Home and Work, Berkeley: University of California Press.

Postanovlenie Pravitel'stva Sankt-Peterburga (2006) O Kontseptsii razvitiya sistemy sotsial'noy zashchity naseleniya Sankt-Peterburga na 2006-2010 gody [On the Concept of the Development of the System of Social Protection of the Population of St. Petersburg for 2006-2010] No. 559 from 16.05.2006.

Romanov P. V. (2005) Strategiya keys-stadi v issledovanii sotsial'nykh sluzhb [The Case Study Strategy in the Study of Social Services]. Sotsiologicheskie issledovaniya [Sociological Studies], (4): 101-110.

Rosstat (2015) Chislennost' pensionerov i sredniy razmer naznachennykh pensiy po vidam pensionnogo obespecheniya i kategoriyam pensionerov na 1 yanvarya 2015 goda [The Number of Pensioners and the Average Size of Pensions by Types of Pensions and Categories of Pensioners by January 1, 2015]. Available at: http://www.gks.ru/free_doc/ new_site/population/urov/urov_p2.htm (accessed 19.06.2017). 
Saint Petersburg Law (2008) O gosudarstvennykh standartakh sotsial'nogo obsluzhivaniya naseleniya Sankt-Peterburga [On State Standards in Social Services for the Population of St. Petersburg] from 30.01.2008.

Sen A. (2004) Razvitie kak svoboda [Development as Freedom], Moscow: Novoe izdatel'stvo.

Tikhonova N. (2004) Social exclusion in Russia. N. Manning, N. Tikhonova (eds.) Poverty and Social Exclusion in the New Russia, Burlington: Ashgate: 109-149. 